\title{
SIX SIGMA AS A TOTAL QUALITY MANAGEMENT TOOL
}

\author{
C.E. Odendaal and S.J. Claasen \\ Department of Industrial and Systems Engineering \\ University of Pretoria \\ Pretoria 0002, South Africa \\ schalk.claasen@eng.up.ac.za
}

\begin{abstract}
The ultimate goal of most companies is to make money and even more money in the future. Part of increasing profits means reducing costs, improving quality and increasing throughput. This paper describes the use of Six Sigma methodologies as a tool in achieving Total Quality Management in the manufacturing environment, with specific emphasis on power transformer manufacturing. The concepts encompassed by Six Sigma are included, their relevance explained and some early results are shared. The measure, analyse, improve and control cycle is the main emphasis of this paper. It is concluded that by adopting Six Sigma as a Total Quality Management tool, company bottom lines are improved.
\end{abstract}




\section{Introduction}

The industry. The power transformer industry in the world can be considered a mature industry. There is an abundance of manufacturing capacity globally. Demand has shifted from its original locations to developing countries. Global competition for these markets is the real issue at present.

The Product. Power transformers are large electrical machines used to transform electrical energy from one potential level to another using magnetic induction. These transformers are highly specialised items manufactured to customer requirements. The requirements are specified using some 20 different parameters with endless variations to each parameter. This gives rise to so many different possible combinations that each unit is tailor designed and manufactured to those requirements.

The manufacturing process. The transformer is manufactured from different components using different processes. The coils are wound with insulated conductor on cylinders of insulation, dried and pressed to size. A core is stacked using sheets of cold rolled grain orientated silicon steel. The coils are assembled on the core and dried in an oven. The coils are then pressed and locked into position. This assembly is then placed into a manufactured tank. The tank is oil filled under vacuum and prepared for test. The transformer is then subjected to a series of tests to confirm compliance to the original specification and to meet the quality standards. After testing the transformer, it is partly disassembled for transport to site where it is erected and subjected to similar tests to confirm correct assembly on site.

The companies. There are two companies under discussion in this paper. The one is a multinational company located in South Africa. The other is an Australian owned company located in Australia.

\section{Relevant Theory}

The Total Quality Management concept. Total Quality Management (TQM) according to Besterfield [1], is the management of the whole to achieve excellence. TQM is the set op principles that guide an organisation to continuously improve. Embedded in the TQM concept is some basic principles. These are:

- Commitment of management to support financially and otherwise;

- Focus on the customer to meet his requirements;

- Involvement of the entire workforce to be trained and implement it;

- A constant drive to improve processes, reduce cycle times, reduce scrap and deliver on time.

- Involve suppliers as an extension to the business;

- Measurements to be taken analysed and controlled.

To satisfy the customer at lower cost would be the ultimate aim.

The Six Sigma concept. Six Sigma technically means a failure rate of 3.4 parts per million, but Chase [2] reckons it's more than just counting defects. She is of the opinion that it is the implementation of a quality culture of strategies, statistics and other tools for improving a 
company's bottom line. From figure 1 it is clear that it is a continuous process of measure, analyse, improve and control.

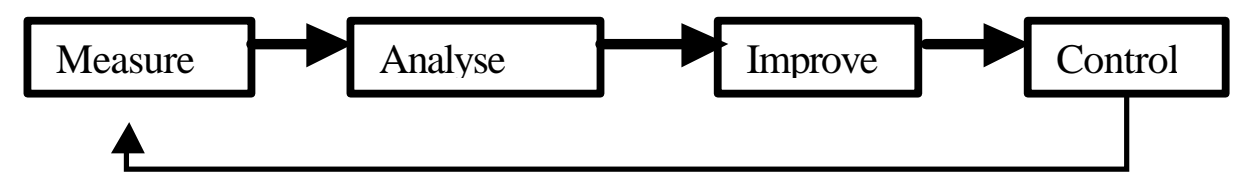

Figure 1 : Six Sigma Cycle of Continuous Improvement

Trained Six Sigma operators are better known as 'Black Belts' and are equipped with knowledge and techniques such as:

- process mapping,

- measurement system analysis,

- graphical analysis,

- capability analysis,

- analysis of variances,

- regression analysis,

- design of experiments,

- statistical process control,

- supply chain management and many more.

Six Sigma Black Belts act as in-house consultants that reduce the cost of poor quality for the company.

Statistical Process Control. Statistical process control (SPC) is a term used for using charts and other statistics to analyse a process. These charts facilitate the identification of common cause variation and special cause variation.

Cost Of Poor Quality. Cost of poor quality (COPQ) is a term that refers to all activities that reduce the profit a company can make. A parallel can be drawn to an iceberg. Some costs are easy to see and others are below the surface. According to Magnusson [3] the tip of the iceberg includes warranty, rejects, scrap, rework and inspection costs. Below the surface lies engineering change orders, long cycle times, time value of money, more set-ups, expediting costs, working capital allocations, lost sales, late delivery, excess inventory, excessive material orders or planning and lost customer loyalty. According to Juran [4] the COPQ in most companies amount to between 20 and $40 \%$ of sales.

Defects per million opportunities. Defects per million opportunities (dpmo) refers to the number of defects that would have been produced had 1 million been manufactured. In most processes it would take forever to produce a million of something, therefore we measure only a sample and use statistics to predict the outcome of the total.

Design of experiment. The design of an experiment (DOE) is a powerful tool in solving variation problems. A DOE according to Modig [5] is a statistical technique used to study the effects of multiple variables simultaneously on the outcome. This technique is also known as factorial experimentation. The effects of the inputs on the output are recorded when the inputs 
are varied purposely in a structured manner. Once the variables have been chosen, the experiment is set up with input levels predetermined.

Variation. "Variation is the business number one enemy!" [5] Variation is found in all processes. There are two types of variation namely common cause variation, which is not predictable and special cause variation of which the cause is more predictable. In SPC charts are used to identify the special cause variations at early stages.

\section{Implementation}

Management buy in. For any change to be implemented successfully the company management need to be committed to the change. For management to be committed they need to be convinced, and there is no better way than money to convince anyone. The implementation of Six Sigma has certain expenditures associated with it. The cost of training Black Belts, the cost of measuring equipment, the cost of keeping a Black Belt employed and then the costs of experiments. All of this is however offset against the gains of reducing the COPQ.

Training. There are different people in the company that need training, and their training differs due to the role they play. Awareness is something that all need to have. This is awareness of the importance of quality to the organisation and then awareness of their role in the implementation of Six Sigma. The operators would need to be trained to take measurements correctly and record them. Management need to be trained on how to interpret the new data/ information that becomes available from the measurements. The most intensive training is that of the Black belts or champions. They are the key to making Six Sigma generate the expected returns. Black Belt training is an intensive thirteen-day course spread over five months. Skills are progressively taught, practised and honed. Four sessions of three days, are held by a master Black Belt. After each session, projects are given as homework. Actual savings with regards to a reduction in COPQ are required. At the end of the training each candidate has to prove that they have saved \$ US 50000 in order to qualify as a Black Belt.

Measurement. We do not know what we do not measure, and if we do not know we cannot control. Therefore measurement is essential in the process of Six Sigma implementation. To go and measure blindly any parameter available would be of no use. Careful analysis of the total process is required. In transformer manufacturing, many different components are manufactured, processed and assembled to make a single product. Between 50 and 150 individual units are produced annually, so there is no mass production to speak of.

Secondly the mistakes made in manufacture are often only visible during the testing stage. By that time rectification is expensive and time consuming. Early detection of problems is required. Measurements cannot be introduced all at once. They have to be phased in. The biggest question is related to "where to start". In Figure 2 the process of transformer manufacturing is portrayed. 


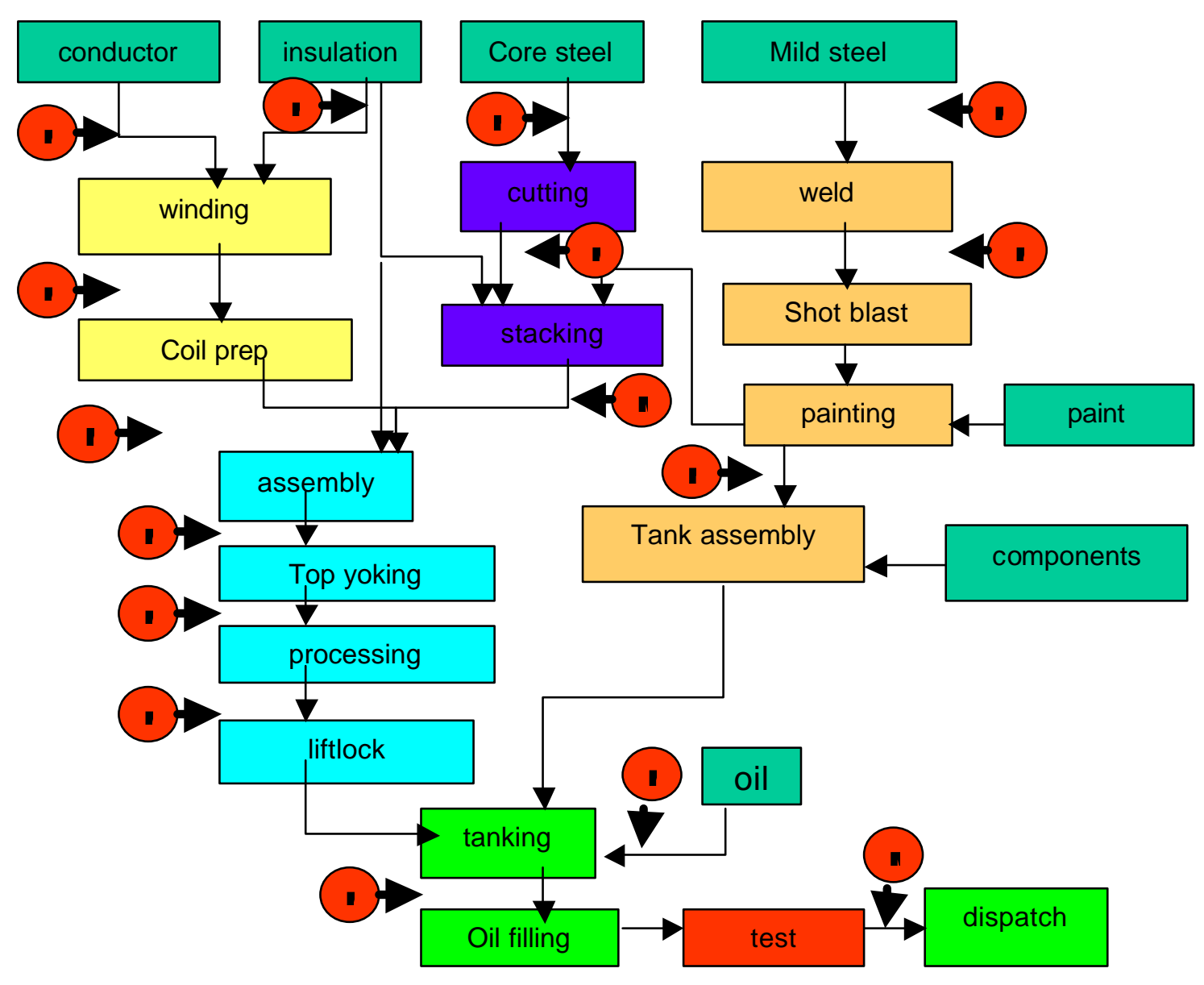

Figure 2 : Power transformer manufacturing process with measurement points

Points of measurement are indicated in figure 2 above. Each point of measurement can have several dimensions to be measured. Each dimension is considered as an opportunity. Some 30 opportunities are identified as being necessary to measure. Measurements are to be made by the person who actually performs the activity. This enables them to correct when out of specification limits and also record their quality level.

Analysis. Measurement without analysis is like having the results of a test, but not opening the envelope to see the result. By performing analysis data is converted to information. After the analysis the "marks" are allocated and it can be concluded if the process is bad, acceptable or good. The focus of attention can then be channelled to have the biggest positive impact.

The analysis can be done using one or more of the statistical tools available. These tools are regression analysis, analysis of variance, Pareto analysis, measurement system analysis, graphical analysis and capability analysis. Pareto analysis would be appropriate when analysing failure causes. The cause with the highest occurrence or cost would be addressed first. Figure 3 shows a typical Pareto analysis. 


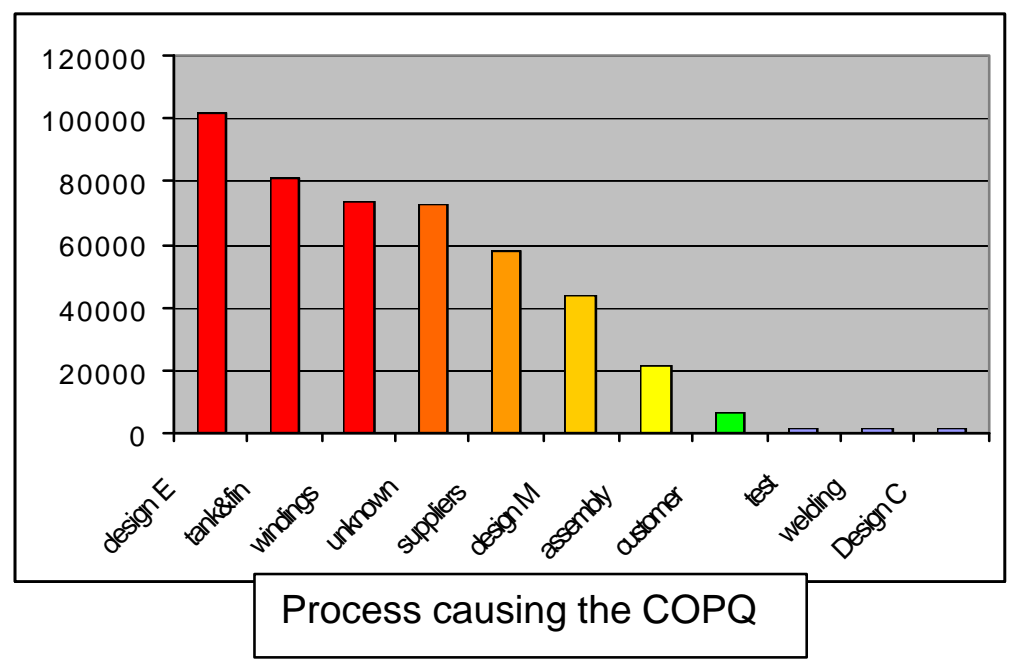

Figure 3 : Pareto analysis of COPQ by processes

Capability analysis would be most useful to determine the capability of a specific process. Figure 4 is an example of such analysis done on a particular process.

\section{Process Capability Analysis for C1}

\begin{tabular}{lr}
\multicolumn{2}{c}{ Process Data } \\
USL & 1.9300 \\
Target & 1.9000 \\
LSL & 1.8700 \\
Mean & 1.8821 \\
Sample N & 50 \\
StDev (ST) & 0.0110949 \\
StDev (LT) & 0.0110949 \\
& \\
& \\
Potential (ST) & Capability \\
Cp & 0.90 \\
CPU & 1.44 \\
CPL & 0.36 \\
Cpk & 0.36 \\
Cpm & 0.47 \\
&
\end{tabular}

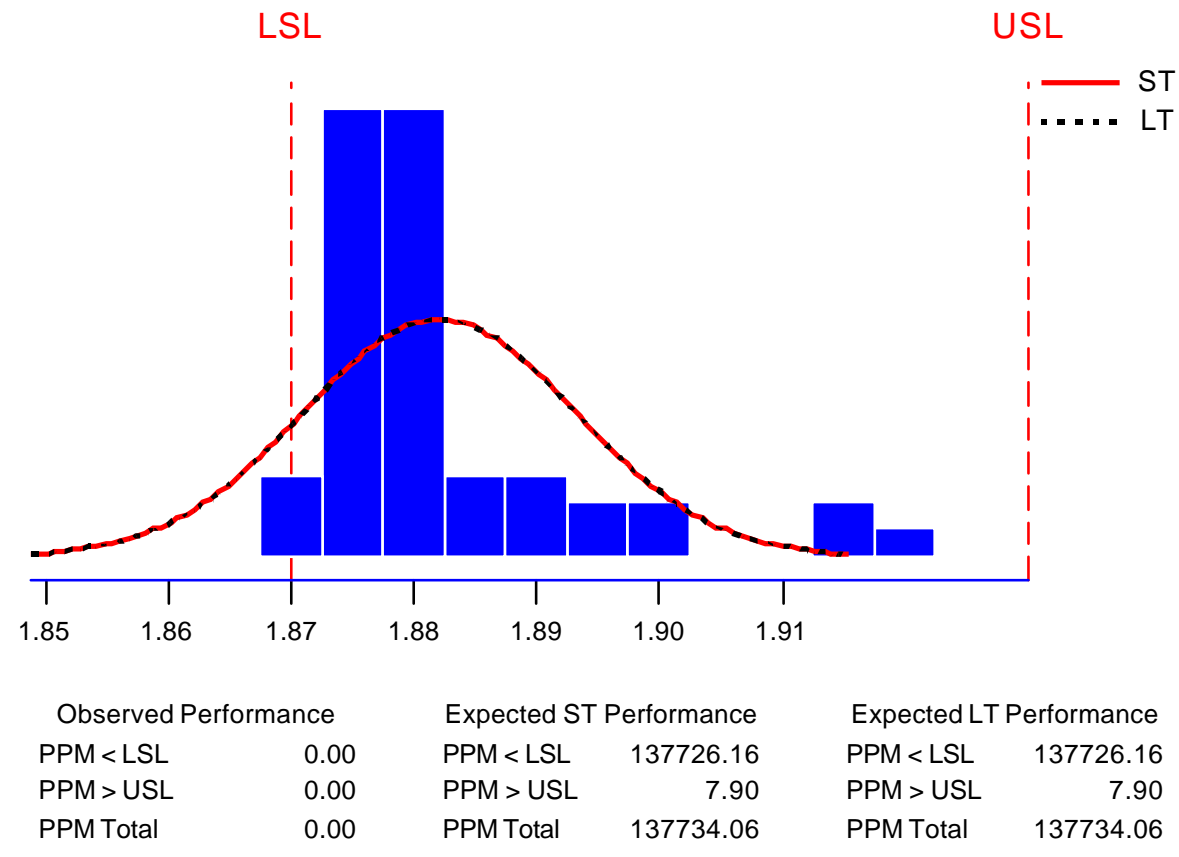

Figure 4 : Capability analysis of copper conductor height

Improvement. Based on the analysis of the different processes and other information, the processes that need the most attention are identified. The company average for all the processes is calculated and all process capabilities below average are due for improvement. 
To focus on the process that would bring about the best return is the obvious choice. Improvements do not just happen by measurement and analysis, a focussed effort with a plan is required. The improvement should be approached as a problem. By following the following steps problems are best solved:

- Define the problem

- Determine the facts

- Identify assumptions

- Determine the causes

- Set the objectives

- What do we want to accomplish?

- What specific results are required?

- What is the minimum, best and probable outcome?

- Generate alternative solutions

- No decisions - just choices

- Determine all potential solutions

- Evaluate the alternatives

- Consider positive and negative consequences

- Determine the "pros" and "cons" of each alternative.

- Critically judge each alternative

- Select a cause of action

- Plan the action

- What, who, when, where and how?

- Have a contingency plan

- Take action

- Evaluate the results.

Factorial experiments or DOE are a key to solving problems using the structure above. By mapping the process the inputs are defined. Measurements turn assumptions into facts. Coefficients for each of the inputs are determined and a formula for the output is generated.

$$
\text { Output }=\mathrm{F}(\text { Input } 1, \text { Input } 2, \text { Input 3, ......, Input n })
$$

This then enables you to adjust the inputs so that the desired output can be achieved. It is important to verify the settings with a trial run before full production takes place.

Control. Once the process parameters are set for the improved output it remains necessary to keep control over it. The way to control such a process is by using SPC. Control charts are used to give early indications of processes going out of control. Control limits are set within the specification limits and certain tests are done on the results to detect early control problems. In essence what you would be looking for are indications of special cause variation. 


\section{Results}

The results achieved can be categorised in different ways.

Project 1 - Bushing manufacture. In this project the number of bushings that failed test were too high. The process was mapped, inputs defined and an experiment done $\mathbf{b}$ find the relationship of some of the parameters. The three parameters that related to the winding machine were the focus points. The experiment revealed that a faster winding speed and higher roller temperature were beneficial in reducing the tangent delta of the wound condenser. The winding time was reduced by 30 percent and the failures reduced by 50 percent.

Project 2 - Coil pressing. One of the important parts of transformer manufacture is the winding of coils. An accurate height is required in the dry state, because this influences parameters like short circuit withstand capability and impedance. There has been recorded over a number of years the adjustment required to size the coils accurately and some trends were noticed. Some types consistently required positive adjustments and others negative adjustments. A years results were analysed, design data added and the results confirmed in figures what was expected. The figures are tabulated below.

\begin{tabular}{|l|c|c|c|}
\hline Winding type & $\begin{array}{c}\text { Mean value of adjustment } \\
\text { in } \mathbf{~ m m}\end{array}$ & $\begin{array}{c}\text { Standard deviation in } \\
\mathbf{~ m m}\end{array}$ & Number in sample \\
\hline Total population & 6.019 & 14.94 & 362 \\
\hline All Helical windings & 14.204 & 11.318 & 125 \\
\hline All Layer windings & 4.956 & 10.058 & 46 \\
\hline HV disc with taps inside & 1.542 & 6.303 & 24 \\
\hline Paper covered disc windings & 2.09 & 11.989 & 100 \\
\hline CTC disc windings & 16.812 & 7.582 & 33 \\
\hline Series loop with CTC & -24.556 & 9.302 & 18 \\
\hline Series loop, paper covered & -11.625 & 8.158 & 16 \\
\hline
\end{tabular}

Table 1 : Adjustments made to coils grouped according to type

This enabled the designers to compensate at the design stage for the different values of adjustment whereby coil preparation time is reduced substantially. The next step on this project is to reduce the variation in the different groups.

Project 3 - Block punch. This is a project of reducing scrap. Blocks are punched out of 1,5 $\mathrm{mm}$ thick insulation material using a mechanical punch. The important parameter is the length of the block. According to the process the scrap percentage should be in the order of 16 percent, but up to 30 percent scrap was produced. By measuring the scrap as an output and changing the inputs it is possible to determine the effect of multiple inputs on the output using a factorial experiment or DOE.

Project 4 - Copper hardening. This project was initiated due to excessive copper scrap being produced. According to engineering calculations 1.5 percent scrap would be normal, but 4.5 percent had been recorded. Measurements of copper dimensions were taken before and after the copper was paper covered. There was an intermediate process of work hardening before paper covering. This gave rise to a reduction in external dimensions of the copper, but 
it was not detected due to the fact that the loss of copper was made up by adding paper. Intermediate measurements were introduced and it was found that 3 percent elongation of the copper took place as an average. The company philosophy was changed to buy copper already hardened and to the right dimension and this saved the 3 percent copper being scrapped.

Overall quality levels. The quality levels of the critical processes were determined by analysing the processes in terms of the dpmo and then expressing them as sigma levels. This enabled the processes that were worse than the average to be singled out and improved.

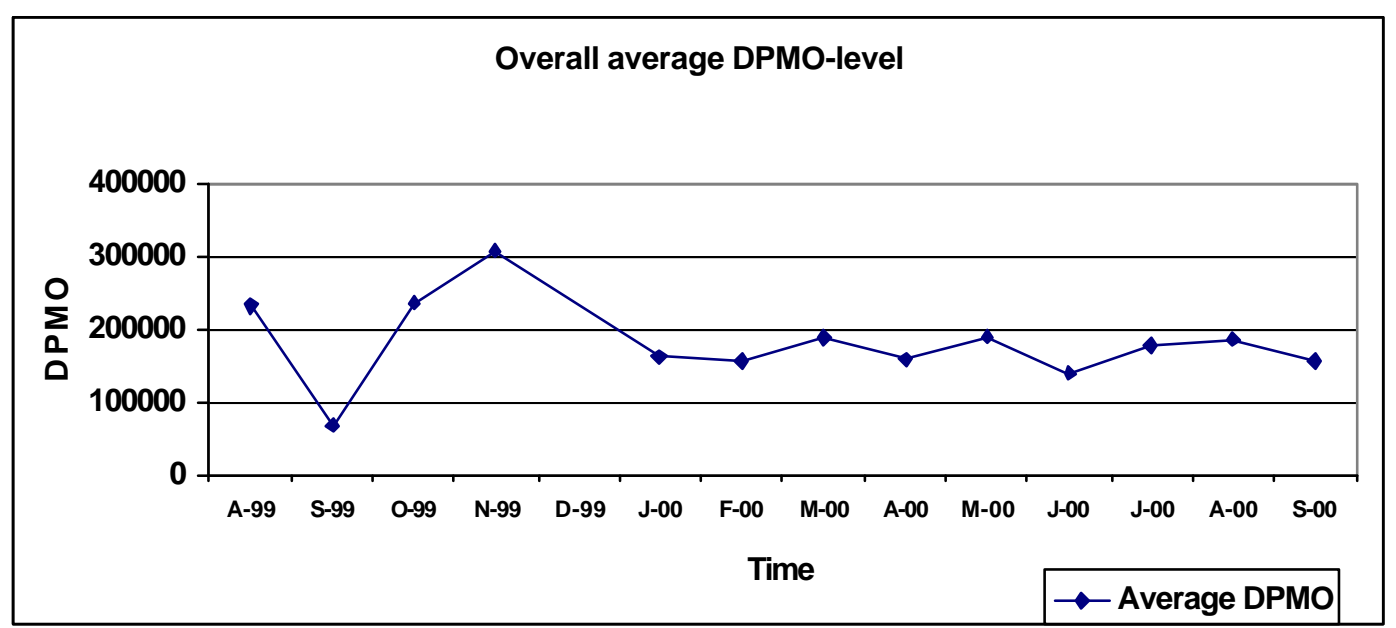

Figure 5 : Overall dpmo of one of the companies over a one year period

The monthly fluctuations of dpmo values are expected since new opportunities were added throughout the year. What is important is the overall trend that should have a negative slope to reflect the improvement.

\section{Conclusions}

It is concluded that by reducing the cost of poor quality, a significant impact can be made on company profits. The first four projects totalled a potential annual saving of nearly $\$ 200000$ US, which averages out to $\$ 50000$ per project. This would be added to net profits since it is a recovery of cost of poor quality.

Measurements change assumptions to facts. By measuring the actual quality levels the areas requiring the most significant improvements could be identified. Quality levels could then be controlled and improved.

\section{References}

[1] Besterfield, D.H., Total Quality Management, Prentice Hall, New Jersey, 1999.

[2] Case, N. Six Sigma Black Belts stamp out tough quality problems, Quality on line, August 1999. http://qualitymag.com/articles/1999/aug99/0899f3.html

[3] Magnusson, K., Six Sigma Quality Book, ABB CHTDM, 1999.

[4] Juran, J.M., Quality Planning and Analysis. $3^{\text {rd }}$ Ed, Mc Graw-Hill, 1993.

[5] Mondig, K., Six Sigma Guide Book, TW Tryckeri, Ludvika, Sweden, 1997. 